Publicación Semestral Pädi No. 12 (2019) 91-94

\title{
Micropits MEMS
}

\author{
José Luis González-Vidal ${ }^{\text {a,*}}$, Mario Alfredo Reyes-Barranca ${ }^{\text {b }}$, Francisco Morales-Jiménez a \\ José Luis calderón Osorno $^{c}$, Ana Larissa Montiel Rodríguez ${ }^{\mathrm{a}}$
}

\author{
a Área Académica de Computación y Electrónica, ICBI, Ciudad del Conocimiento, Carretera Pachuca-Tulancingo Km. 4.5, Col. Carboneras, Mineral de la \\ Reforma, Hidalgo, México, C. P. 42184. \\ ${ }^{b}$ Centro de Investigación y de Estudios Avanzados del Instituto Politécnico Nacional, Departamento de Ingeniería Eléctrica, Ave. Instituto Politécnico Nacional \# \\ 2508, Col. Sn. Pedro Zacatenco, Ciudad de México, México, C.P. 07360. \\ ${ }^{c}$ Instituto Politécnico Nacional, Unidad Profesional Interdisciplinaria de Ingeniería Campus Hidalgo, Kilómetro 1.500, Actopan - Pachuca, San Agustín Tlaxiaca, \\ Hidalgo, México, C. P. 42162.
}

\begin{abstract}
Micropits are MEMS widely used in gas sensors, because they provide thermal isolation, Micropits will be used for gas microsensors, and polysilicon microheater and gas sensor thin film will be deposited later. Today gas sensors have several applications in manufacturing \& industry, such as, automotive, medicine/biomedical, consumer products, aerospace, chemical, optical displays, fluidics, wireless and optical communications. Three sized Micropits were developed. Micropits were designed by L-Edit V16 of Tanner EDA and fabricated using wet etching. MEMS fabrication consists of thin film deposition and patterned of several geometric structures. For $\mathrm{Si}$ substrate etching three layers $\mathrm{SiO}_{2} / \mathrm{Si}_{3} \mathrm{~N}_{4} / \mathrm{SiO}_{2}$ were deposited and patterned. They were used as a mask. Micropit pattern was transferred by lift off technique. $\mathrm{SiO}_{2}, \mathrm{Si}_{3} \mathrm{~N}_{4}$ layers and $\mathrm{Si}$ substrate were etched by $\mathrm{HF}_{3} \mathrm{H}_{3} \mathrm{PO}_{4}$ and $\mathrm{KOH}$ solutions. Si substrate has $7 \mu \mathrm{m} / \mathrm{h}$ etching rate. Micropit micrographs were obtained by scanning electronic microscopy (SEM).
\end{abstract}

Keywords: MEMS, micropits, etching.

\section{Introduction}

The meanning of MEMS is micro-electro-mechanical systems. MEMS use microelectronical technology to develop by mean of deposition, patterned and etching of some materials to make very tiny electronic and structures on a scale ranging of microns. Usually these systems have electrical inputs and outputs. The most important characteristics of MEMS are low power comsuption and batch fabrication techniques similar to integrated circuits electronic industry. For all these reasons, development of miniature devices like in manufacturing and industry, such as automotive, consumer products, aerospace, chemical, applications, among others, requires components with minimum power consumption and better performance. As is well known MEMS may be miniaturized structures, sensors, actuators, and electronics circuits, the most interesting elements are the microsensors and microactuators. Microsensors and microactuators are categorized as transducers, by definition, transducers are devices that convert a kind of energy to another one. on the other hand microsensors can convert a measured physical signal into an electrical signal.

Today MEMS are applied in the most of ours electronical devices and gadgets, and they are very famous as inertial sensors, such as microaccelerometers and microgyroscopes. The worldwide MEMS market is predicted to reach more than top 20 billion U.S. dollars by this year.
Another type of MEMS applications are gas sensors based on thin films, due thin films must be heathed, MEMS micropits are widely used to provide thermal isolation, because the most of micro gas sensor thin films need to be heated above room temperature even several hundred grades. Micropits had been used for gas sensors forming a micro hot plate (membrane) which held up both a microheater and a gas sensor thin film. The membrane usually is supported by four cross shaped arms of $\mathrm{SiO}_{2}$. Micropits had been patterned by etching of p-type silicon wafers with $\langle 100\rangle$ crystallographic orientation, silicon is used as substrate due their semiconductor and mechanical characteristics. (Senturia, 2001; Petersen, 1982; GonzálezVidal, et al, 2005a , b; Maluf et al, 2004; Reyes-Barranca et al, 2009; Sze et al, 2007; Hongwei, 2016).

\section{Development}

The three micropits were designed by L-Edit ${ }^{\circ}$ V16 of Tanner EDA®, using a work station HP Z440®, processor Intel ${ }^{\circledR}$ Xenon ${ }^{\circledR}, 8 \mathrm{~GB}$ RAM, at $3.1 \mathrm{GHZ}$. Figure 1 shows three micropits with different dimensions: figure 1a) first (smaller) micropit with $100 \mu \mathrm{m} \times 100 \mu \mathrm{m}$, with a squared centered membrane of $20 \mu \mathrm{m} \times 20 \mu \mathrm{m}$ and supporting cross shaped arms with width of $7.1 \mu \mathrm{m}$; figure $1 \mathrm{~b}$ ) second ( medium) micropit with $200 \mu \mathrm{m} \mathrm{x} \mathrm{200,} \mathrm{with} \mathrm{a} \mathrm{squared} \mathrm{centered}$ membrane of $40 \mu \mathrm{m} \times 40 \mu \mathrm{m}$ and supporting cross shaped arms of $14.1 \mu \mathrm{m}$; figure 1c) third (largest) micropit with 300

\footnotetext{
* Autor en correspondencia.

Correo electrónico: j1vida1@uaeh. edu .mx (José Luis González Vidal).
} 


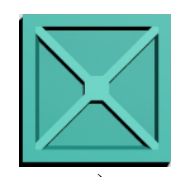

a)

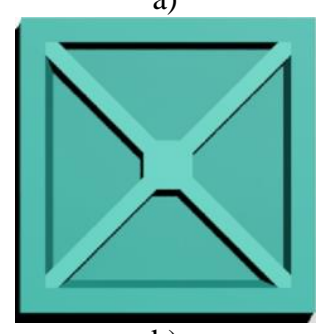

b)

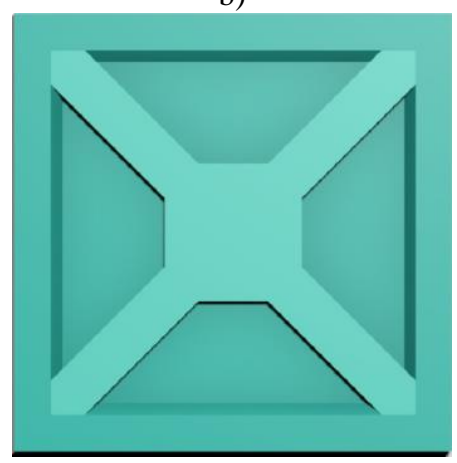

c)

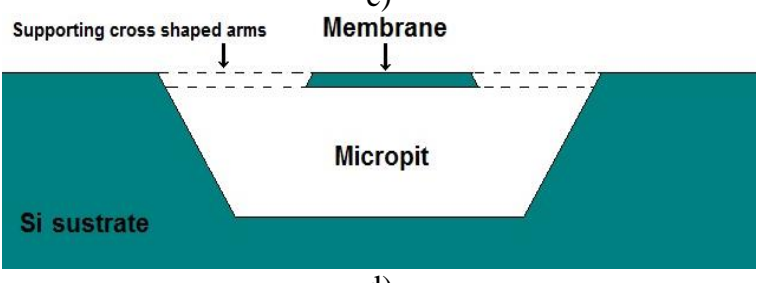

d)

Figure 1 Three different sized micropits. a) Smaller micropit, b) medium sized micropit, c) largest micropit and d) Micropit cross section view.

$\mu \mathrm{m} \times 300 \mu \mathrm{m}$, with a squared centered membrane of $100 \mu \mathrm{m} x$ $100 \mu \mathrm{m}$, and supporting cross shaped arms widths $35.4 \mu \mathrm{m}$; figure 1d) shows the crosssection of the micropit. There are several eatching techniques and etchants for patterning the micropit, like dry or wet etching techniques and systems like deep reactive ion reactive (DRIE) that can also be used for micropit etching (Deepak et al, 2016; Dhineshkaarthi et al, 2017; González-Vidal et al, 2005b, 2018; Vázquez Acosta \& et al, 2012a).

Wet techniques use suitable chemical solutions such as trimethyl ammonium hydroxide (TMAH) or potassium hydroxide $(\mathrm{KOH})$ among others. It is well known that depending on the patterned material there is a variety of etchant substances and techniques used. Also, lift off process is used to pattern several materials that are difficult to achieve with plasmas. Commonly, anisotropic wet etching is used for Micropits patterning because this technique exhibits crystallographic orientation dependent each rates (GonzálezVidal \& et al, , 2005; Pandya et al, 2015; Gatzen et al, 2015; Hongwei, 2016; Beeby et al, 2004; Bhansali et al, 2012; Reyes-Barranca et al, 2010; Vázquez-Acosta et al, 2012b).

In the case here presented, patterning of a silicon substrate was made using as protecting layers three deposited layers of silicon oxide/ silicon nitride/ silicon oxide $\left(\mathrm{SiO}_{2} / \mathrm{Si}_{3} \mathrm{~N}_{4} /\right.$ $\mathrm{SiO}_{2}$ ); the lower $\mathrm{SiO}_{2}$ layer was grown by thermal oxidation, the $\mathrm{Si}_{3} \mathrm{~N}_{4}$ layer was deposited by the LPCVD technique using silane $\left(\mathrm{SiH}_{4}\right)$ and ammoniac $\left(\mathrm{NH}_{3}\right)$, and the upper $\mathrm{SiO}_{2}$ layer wasdeposited using $\mathrm{SiH}_{4}$ and $\mathrm{O}_{2}$. After these layers were deposited, the micropit pattern was defined with photolithography and the definition process was completed by lift off. Next, the upper oxide layer was etched with hydrofluoric acid (HF), followed by the etching of the $\mathrm{Si}_{3} \mathrm{~N}_{4}$ layer with phosphoric acid $\left(\mathrm{H}_{3} \mathrm{PO}_{4}\right)$, and finally etching the last layer of $\mathrm{SiO}_{2}$ again with $\mathrm{HF}$. This process defines the areas where silicon is unprotected and ready to be etched away using potassium hydroxide $(\mathrm{KOH})$, releasing at last the membrane with the micro-hot plate (González-Vidal \& et al, 2005, 2006; Hongwei, 2016; Varadan et al, 2006; VázquezAcosta et al, 2012c).

On the other hand, micropit micrographs were obtained by a SEM model JSM-6300 JEOL®. Figure 2 shows the largest micropit and a detail, in Figure 2a both cross shaped arms and inverted truncated pyramid obtained can be noticed, also micropit floor is completely flat and membrane has not been patterned yet, but in figure $2 \mathrm{~d}$ a corner detail is shown, then very steep slopes are appreciated and the shadow of cross shaped arm is visible.

Furthermore, the medium sized micropit resulted in an almost completely released membrane. Figure 3 a shows the partial etching of silicon under membrane. Although still incomplete, it went further beneath the membrane in comparison with the larger structure and there remains a little hillock keeping the membrane unreleased. Figure $3 \mathrm{~b}$ shows a detail of medium micropit and its membrane by SEM. In this case, a flat floor can be noticed, too.

Finally, figure 4 shows the smaller micropit, where the $\mathrm{Si}$ under the membrane was almost etched away resulting in steep walls, a smooth bottom surface and a membrane almost released (figure $4 \mathrm{a}$ ). Figures $4 \mathrm{~b}-\mathrm{c}$ show two broken arms after the etching process and the membrane, because $\mathrm{KOH}$ had etched the $\mathrm{Si}$ substrate and the $\mathrm{Si}_{3} \mathrm{~N}_{4}$ mask, giving an indication that the size and width of the geometries used in this membrane were not optimum for this kind of micromachining technique due etching time was too long. 


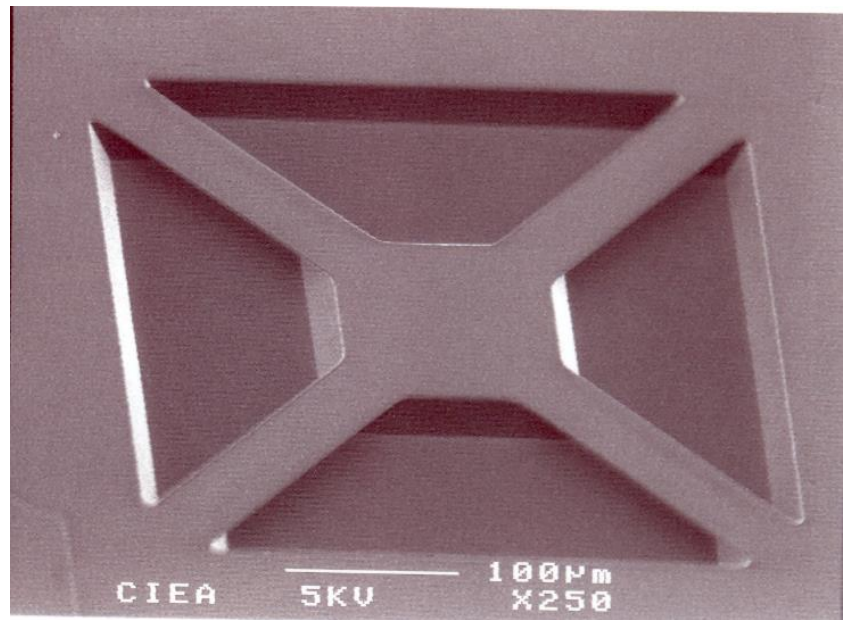

a)

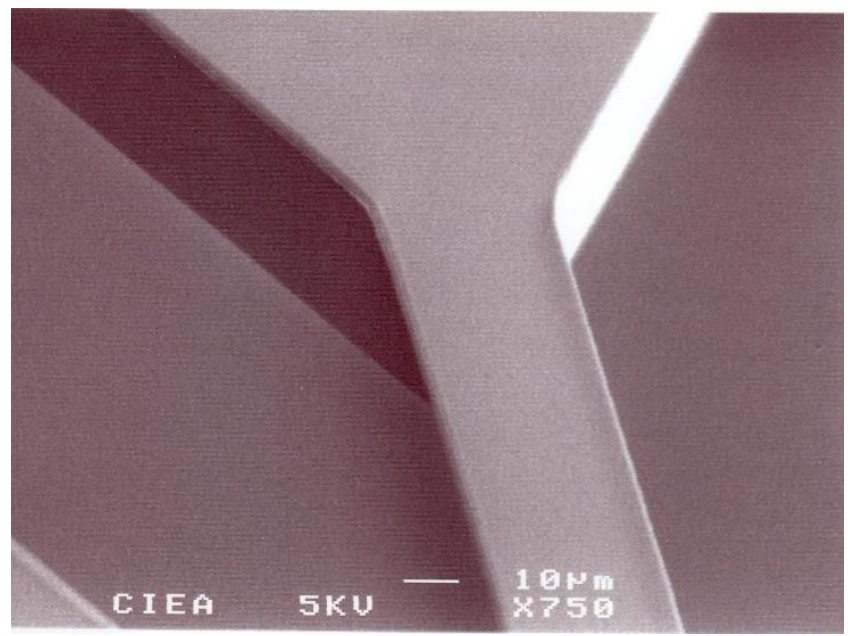

b)

Figure 2 Largest micropit, a) Entire micropit by SEM, b) detail of a largest micropit corner by SEM.

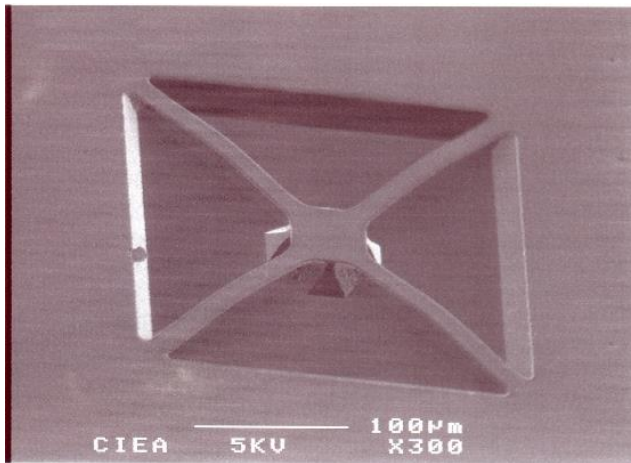

a)

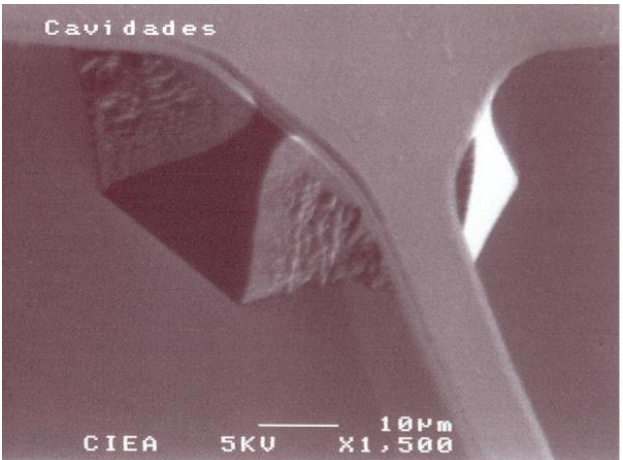

b)

Figure 3 Medium sized micropit, a) Entire medium micropit by SEM, b) detail of medium micropit and membrane by SEM.

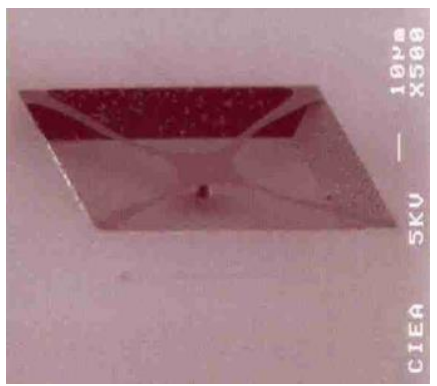

a)

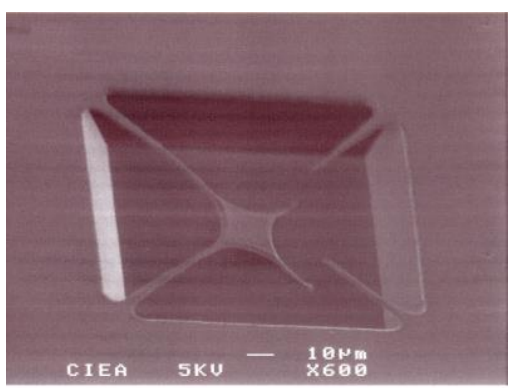

b)

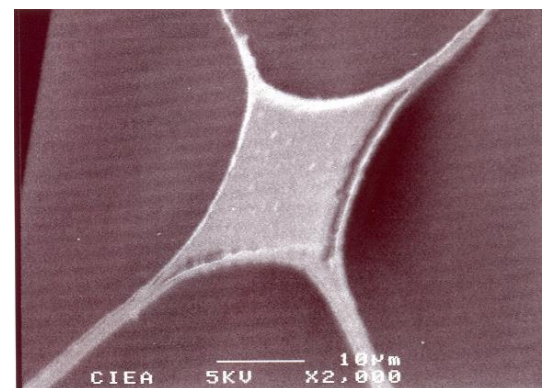

c)

Figure 4 Smallest sized micropit, a) Entire smallest micropit by SEM, b) Smallest micropit, membrane and arms etched and c) detail of smallest micropit with membrane and arms etched.

\section{Conclusions}

MEMS micropits have several applications as micro structures; one of them is to provide a membrane for thermal isolation to semiconductor gas sensor systems based on thin films with micro hot plate and microheaters. The gas sensors, in this case, operate at high temperature while the associated electronics used for temperature control or signal conditioning should be at room temperature. Three micropits with different sizes were proposed to carry out micropits by etching techniques. A membrane consisting of a stack with three layers $\left(\mathrm{SiO}_{2} / \mathrm{Si}_{3} \mathrm{~N}_{4} / \mathrm{SiO}_{2}\right)$ was configured for the experiment. A lift off technique was used to pattern the micropit areas and $\mathrm{HF}, \mathrm{H}_{3} \mathrm{PO}_{4}$ and $\mathrm{KOH}$ were used as wet etchant for 
micromachining the membrane. SEM figures of micropits are shown, as three micropits are in the same substrate. The etching rate produces different results due to different dimensions of the micropits.

\section{Resumen en español}

\section{Microfosos MEMS}

\section{Resumen}

Los microsfosos son MEMS ampliamente usados en microsensores de gases, debido a que les proporcionan aislamiento témico. Los microfososo será utilizados en un proceso posterior cuando se depositen un microcalefactor de polisilicio y una película delgada sensora de gas. Hoy en día, los sensores de gas tienen múltiples aplicaciones en procesos de manufactura y en la industroa, principalmente en la automotríz medicina/ biomédica, de productos de consumo, aeroespacial, química, pantallas opticas, fluídica, inalámbrica y comunicaciones ópticas. En este trabajo se desarrollaron tres microfosos MEMS de diferentes tamaños, fueron deseñados con el software L-Edit V16 de Tanner EDA y, fabricados por métodos de grabado húmedo. La fabricación de los MEMS consiste del depósito de películas delgadas y el grabado y modelado de estructuras de geometrías diversas. Para el grabado de sustrato de silicio, se depositaron y grabaron tres capas de $\mathrm{SiO}_{2} / \mathrm{Si}_{3} \mathrm{~N}_{4} / \mathrm{SiO}_{2}$, las cuales se usaron como mascarillas. El modelo del microfoso se transfirió por la técnica de fotolitografía, las capas de $\mathrm{SiO}_{2}, \mathrm{Si}_{3} \mathrm{~N}_{4}$ y el sustrato de $\mathrm{Si}$ fueron grabados con soluciones de $\mathrm{HF}, \mathrm{H}_{3} \mathrm{PO}_{4}$ and $\mathrm{KOH}$ respectivamente. La razón de grabado del silicio fue de 7 $\mu \mathrm{m} / \mathrm{h}$. Las micrografías de los microfosos fueron tomadas con un microscopio de barrido electrónico (SEM).

Palabras clave

Grabado, MEMS, microfosos.

\section{References}

Beeby, S., Ensell, G., Kraft, M., \& White, N. (2004). MEMS Mechanical Sensors. Norwood, MA: Artech House, www.artechhouse.com.

Bhansali, S., \& Vadusev, A. (2012). MEMS for Biomedical Applications. Sawston, Reino Unido: Woodhead Publishing, UK, www.elsevier.com/books/mems-for-biomedicalapplications/bhansali/978-0-85709-129-1.

Deepak, B., \& et al. (2016). Low Actuating Voltage Spring-Free RF MEMS SPDT Switch. Journal of Electrical and Computer Engineering, 2016, 1-7. doi:http://dx.doi.org/10.1155/2016/7984548.

Dhineshkaarthi.K, Preeth, S. L., \& Kumar, R. (2017). MEMS Cantilever based identification of Carcinogenic MZN. 2017 International Conference on Electrical, Instrumentation and Communication Engineering (ICEICE2017) (págs. 1-4). Karur, India: IEEE. doi:10.1109/ICEICE.2017.8191863.
Gatzen, H. H., \& Leuthold, V. S. (2015). Micro and Nano Fabrication, Tool and Processes. Springer. doi:DOI 10.1007/978-3-662-44395-8.

González-Vidal, J. L. (31 de Marzo de 2006). Aplicación de estructuras micro-electro-mecánicas (MEM's) con tecnología s, para sensores de parámetros físicos. doctoral thesis. Mexico City, Mexico, CINVESTAV-IPN, www.vlsilab.cinvestav.mx/files/GonzalezVidal_PhD_marb.pdf.

González-Vidal, J. L., \& et al. (2005). Gas Microsensing System with a FGMOS on a MEM Microstructure. Microthecnologies for the New Milenium. Sevilla, Espain.

González-Vidal, J. L., Reyes-Barranca, A., \& Calleja-Arriaga, W. (2005) Technological processes for Micro-Heater and Micro-Hot-Plate in the implementation of a MEM gas sensor. 2nd International Conference on Electrical and Electronics Engineering (págs. 440-443). México: IEEE.

González-Vidal, J. L., Reyes-Barranca, M. A., \& Vázquez-Acosta, E. N. (2018). Conditioning and Signal Amplification Stages for a Smart Gas Microsensor MEMS. Pistas educativas, 39(118), 621-336. http://www.itcelaya.edu.mx/ojs/index.php/pistas/article/view/1193.

Hongwei, Q. (2016). CMOS MEMS Fabrication Technologies and Devices Micromachines. Micromachines, 7(14), doi:10.3390/mi7010014.

Maluf, N., \& Williams, K. (2004). An Introduction to Microelectromechanical Systems Engineering, Second Edition, (2nd ed.). Norwood, MA: Artech House Inc. http://www.artechhouse.com.

Pandya, H., Park, K., \& Desai, J. P. (2015). Design and fabrication of a flexible MEMS-based electromechanical sensor array for breast cancer diagnosis. J Micromech Microeng, 25(7), 1-28. doi:DOI: 10.1088/0960-1317/25/7/075025.

Petersen, K. (Mayo de 1982). Silicon as a Mechanical Material. Proceedings of the IEEE, 70(5), 420 - 457. doi:10.1109/PROC.1982.12331.

Reyes-Barranca, M. A., \& et al. (2009). Floating Gate Mosfet Circuit Design for a Monolithic MEMS Gas Sensor. SFORUM 2009 9TH MICROELECTRONICS. Natal, Brasil.

Reyes-Barranca, M. A., \& et al. (2010). Using a Floating-Gate MOS Transistor as a Transduce in a MEMS Gas Sensing. Sensors, 10(11), 10413-10434. doi:10.3390/s101110413.

Senturia, S. D. (2001). Microsystem Desing. Kluvert Academic Publishers.

Sze, S. M., \& Ng, K. (2007). Physics of Semiconductor Devices (3rd. ed.). John Wiley \& Sons Ltd, New Jersey, USA.

Varadan, V. K., Vinoy, K., \& Gopalakrishnan, S. (2006). Smart Material Systems and MEMS: Design and Development Methodologies, John Wiley \& Sons Ltd, Chichester, England, Chichester, England, www.wiley.com.

Vázquez-Acosta, E. N., \& et al. (2012). Simplified Adjusting and Simulation of a Pseudo Gaussian Function in Voltage Domain Generated with FGMOS Transistors on Circuit Simulation Software Exportable to a Multi Domain Platform. 9th International Conference on Electrical Engineering, Computing Science and Automatic Control (CCE 2012). Mexico City.

Vázquez-Acosta, E. N., \& et al. (2012). Performance Evaluation of a Temperarure Control Stage Used on a Semiconductor Gas Sensor 3d Electrothermal Model Through Simulink. En S. C. Chakravarty, \& S. C. Chakravarty (Ed.), Technology And Engineering Aplications Of Simulink (págs. 167-188). Rijeka, Croatia: Intech. www.intechopen.com/books/technology-and-engineering-applicationsof-simulink/performance-evaluation-of-a-temperature-control-stageused-on-a-semiconductor-gas-sensor-3d-elec.

Vázquez-Acosta, E. N, \& et al. (2012). Release Optimization of Suspended Membranes in Mems. En Micromachining Techniques for Fabrication of Micro and Nano Structures (págs. 183-204). Zagreb, Croacia: Intech. 